\title{
A State Variable Method for the Realization of Universal Current-Mode Biquads
}

\author{
Raj Senani ${ }^{1}$, Kasim Karam Abdalla ${ }^{2}$, Data Ram Bhaskar ${ }^{2}$ \\ ${ }^{1}$ Division of Electronics and Communication Engineering, Netaji Subhas Institute of Technology, Delhi, India \\ ${ }^{2}$ Department of Electronics and Communication Engineering, \\ Faculty of Engineering and Technology, Jamia Millia Islamia, New Delhi, India \\ E-mail:senani@nsit.ac.in,kasimkaa.11@gmail.com,dbhaskar@jmi.ac.in \\ Received May 26, 2011; revised July 14, 2011; accepted July 21, 2011
}

\begin{abstract}
A state variable method of converting single-resistance-controlled-oscillators (SRCO), into universal current-mode biquad (offering realizations of all the five standard filter functions namely, low pass, band pass, high pass, notch and all pass) has been highlighted. The workability of the exemplary implementation of the derived current-mode universal biquad has been demonstrated by PSPICE simulation results based upon 0.35 $\mu \mathrm{m}$ technology. It is expected that the proposed method can be applied to other SRCOs to generate other multifunction filter structures.
\end{abstract}

Keywords: Analog Electronics, Circuit Theory and Design, Current Mode Circuits, Universal Biquads, Current Conveyors

\section{Introduction}

Current-mode universal filters employing current conveyors $(\mathrm{CC})$ and their many variants have been extensively investigated during the past two decades for instance, see [1-19] and those cited therein. Current-mode universal filters can be broadly classified in two categories namely the single input multi-output (SIMO)-type ([11-18]) and the multiple-input-single-output (MISO)type $([5,10,14,19])$. It may be mentioned that while most of the proposers of current-mode (CM) universal filters have come up with a specific topology rather than disclosing any general method of systematic derivation of such filters. It may also be noted that while a general method for realizing SIMO-type CM universal filters has been known earlier [20], to the best knowledge of the authors, any systematic method of synthesizing MISOtype CM universal biquads has not been reported explicitly in the open literature yet. The purpose of this paper is to fill this void.

The main object of this paper is to present a state variable method by which a given single resistance controlled oscillator (SRCO) can be re-configured as a multiple-input-single-output (MISO)-type current-mode (CM) universal biquad. Although the method to convert a SRCO into universal current-mode biquad proposed here might appear simple but it has not been explicitly published in the open literature earlier.

\section{The Proposed Method}

Although the proposed method is quite general and can be applied to any given SRCO using any kind of active element, we illustrate the method by choosing an earlier proposed SRCO as an example using fully differential second generation current conveyor (FDCCII) as an active element.

It may be recalled that a FDCCII and its applications for analog VLSI were introduced by El-Adawy, Soliman and Elwan in [1]. FDCCII has since then been used in realizing various signal processing and signal generation circuits for instance, see [1-6]. Simultaneously, improved implementations of FDCCII have also been advanced; see [7] and [8].

Some time back, Chang, Al-Hashimi, Chen, Tu and Wan [2] presented two novel single-resistance-controlledoscillators (SRCO) using a single FDCCII and all grounded passive elements, which is advantageous for integrated circuit implementation.

Consider now one of the CM SRCOs from [2] (Figure 1 therein). The condition of oscillation (CO) for this circuit is given by $R_{1}=R_{3}$ and frequency of oscillation 
(FO) is given by $\omega_{0}=1 / \sqrt{R_{2} R_{3} C_{1} C_{2}}$.

With all its y-input terminals unconnected, the circuit can be redrawn as shown in Figure 1(a).

Note that with $Y_{1}$ connected to $Z+$ and $Y_{3}$ connected to $Z$ - with $Y_{2}$ and $Y_{4}$ connected to ground, one obtains the SRCO of Figure 1 of [2].

To synthesize a filter providing independent control of $\omega_{0}$ (say, by the resistor $R_{2}$ ) and independent control of bandwidth $\left(\omega_{0} / Q_{0}\right)$ (say, by the resistor $R_{1}$ ), one must have a transfer function $\frac{I_{\text {out }}}{I_{\text {in }}}=\frac{N(s)}{D(s)}$ with its characteristic polynomial $D(s)$ given by

$$
D(s)=s^{2}+\left(\frac{\omega_{0}}{Q_{0}}\right) s+\omega_{0}{ }^{2}=s^{2}+\frac{s}{R_{1} C_{2}}+\frac{1}{C_{1} C_{2} R_{2} R_{3}}
$$

From the above, the characteristic equation of the circuit (assuming zero input) is given by

$$
s^{2}+\frac{s}{R_{1} C_{2}}+\frac{1}{C_{1} C_{2} R_{2} R_{3}}=0
$$

It can be easily worked out that assuming that the circuit to be synthesized has to have two capacitors and three resistors only, if the voltages across the assumed capacitors $C_{1}$ and $C_{2}$ are taken as $x_{1}$ and $x_{2}$ respectively

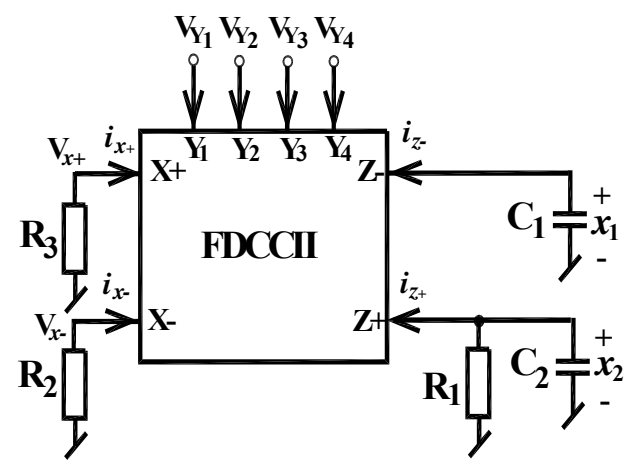

(a)

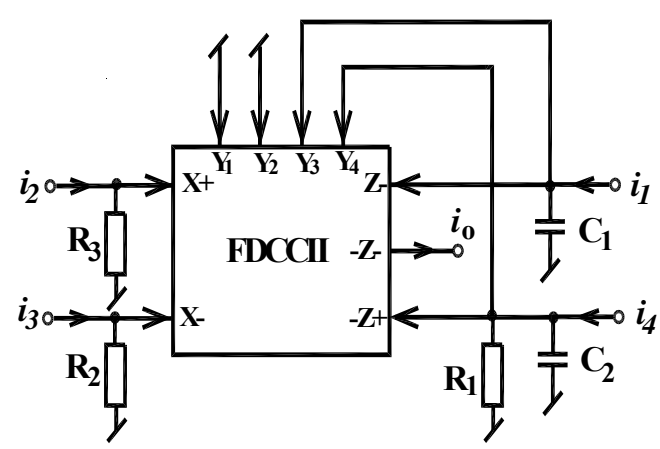

(b)

Figure 1. (a) Circuit arrangement with un-committed $y$-inputs of FDCCII, derived from SRCO of [2]; (b) An exemplary MISO-type universal CM biquad. such a circuit should be characterized by the following matrix state equation

$$
\left[\begin{array}{l}
\frac{\mathrm{d} x_{1}}{\mathrm{~d} t} \\
\frac{\mathrm{d} x_{2}}{\mathrm{~d} t}
\end{array}\right]=\left[\begin{array}{cc}
0 & \frac{1}{C_{1} R_{2}} \\
-\frac{1}{C_{2} R_{3}} & -\frac{1}{C_{2} R_{1}}
\end{array}\right]\left[\begin{array}{l}
x_{1} \\
x_{2}
\end{array}\right]=[A]\left[\begin{array}{l}
x_{1} \\
x_{2}
\end{array}\right]
$$

so that the consequent characteristic equation

$$
\operatorname{det}\{s[I]-[A]\}=0
$$

would, indeed, result in the characteristic Equation (2).

Equation (3) can now be re-arranged as follows:

$$
\begin{gathered}
C_{1} \frac{\mathrm{d} x_{1}}{\mathrm{~d} t}=\frac{x_{2}}{R_{2}} \\
C_{2} \frac{\mathrm{d} x_{2}}{\mathrm{~d} t}=-\frac{x_{1}}{R_{3}}-\frac{x_{2}}{R_{1}}
\end{gathered}
$$

The above equations can be considered to be the node equations (NE) of the circuit to be synthesized. In view of the FDCCII characterization, which is given by the equations: $i_{Y k}=0, k=1-4 ; \quad v_{X+}=\left(v_{Y 1}-v_{Y 2}+v_{Y 3}\right)$, $v_{X-}=\left(-v_{Y 1}+v_{Y 2}+v_{Y 4}\right), \quad i_{-Z+}=-i_{X+}, \quad i_{Z-}=i_{X-}$, the circuit shown in Figure 1(a) ( where terminal $Z+$ is replaced by $-Z^{+}$) is characterized by the following equation

$$
\begin{aligned}
& {\left[\begin{array}{c}
\frac{\mathrm{d} x_{1}}{\mathrm{~d} t} \\
\frac{\mathrm{d} x_{2}}{\mathrm{~d} t}
\end{array}\right]=\left[\begin{array}{cc}
0 & 0 \\
0 & -\frac{1}{C_{2} R_{1}}
\end{array}\right]\left[\begin{array}{l}
x_{1} \\
x_{2}
\end{array}\right]} \\
& +\left[\begin{array}{cccc}
-\frac{1}{C_{1} R_{2}} & \frac{1}{C_{1} R_{2}} & 0 & \frac{1}{C_{1} R_{2}} \\
-\frac{1}{C_{2} R_{3}} & \frac{1}{C_{2} R_{3}} & -\frac{1}{C_{2} R_{3}} & 0
\end{array}\right]\left[\begin{array}{l}
v_{Y 1} \\
v_{Y 2} \\
v_{Y 3} \\
v_{Y 4}
\end{array}\right]
\end{aligned}
$$

where voltages across capacitors $C_{1}$ and $C_{2}$ are chosen as state variables $x_{1}$ and $x_{2}$ respectively. If the various Y-terminal voltages of FDCCII are chosen as:

$$
v_{Y 1}=0, v_{Y 2}=0, v_{Y 3}=x_{1}, v_{Y 4}=x_{2}
$$

then it can be verified that resulting state equations will be same as in Equations (5) and (6).

After having made the above state variable assignment and by appropriately connecting the required external terminals of the FDCCII in accordance with the requirements in Equation (8), a non-autonomous circuit with multiple-inputs and single-output (MISO) is subsequently created by augmenting the circuit with four external current input signals $i_{1}, i_{2}, i_{3}$ and $i_{4}$ and extending the FDCCII to have one additional Z+ output terminal (henceforth to be referred as multiple output FDCCII (MO-FDCCII)). The output current of the resulting cir- 
cuit (shown in Figure 1(b)) is found to be:

$$
i_{0}=\frac{-i_{3}\left(s^{2}+\frac{s}{C_{2} R_{1}}\right)+\left(i_{2}+i_{4}\right) \frac{s}{C_{2} R_{2}}-i_{1} \frac{1}{C_{1} C_{2} R_{2} R_{3}}}{s^{2}+\frac{s}{C_{2} R_{1}}+\frac{1}{C_{1} C_{2} R_{2} R_{3}}}
$$

Note that the $D(s)$ of (9) is exactly same as (1).

The five filter responses can be realized from the circuit of Figure 1(b) as follows: Low pass (LP): making $i_{2}=i_{3}=i_{4}=0$ and taking $i_{1}=i_{i n}$. Band pass (BP): making $i_{1}=i_{3}=0$ and taking one of $i_{2}$ or $i_{4}$ as $i_{i n}$. High pass (HP): making $i_{1}=0$ and taking $i_{2}$ or $i_{4}=i_{3}=i_{i n}{ }^{1}$ along with $R_{2}=R_{1}$. Notch: making $i_{2}$ or $i_{4}=i_{1}=i_{3}=i_{\text {in }}$ along with $R_{2}=R_{1}$. All pass (AP): making $i_{1}=i_{2}=i_{3}=i_{4}=i_{i n}$ along with $R_{2}=R_{1}$.

The various parameters of the realized filters are given by

$$
\begin{gathered}
\omega_{0}=\sqrt{\frac{1}{C_{1} C_{2} R_{2} R_{3}}} ; \mathrm{BW}=\frac{1}{C_{2} R_{1}} ; Q_{o}=R_{1} \sqrt{\frac{C_{2}}{C_{1} R_{2} R_{3}}} \\
H_{0}=\left\{\begin{array}{l}
\frac{R_{1}}{R_{2}} \text { for } \mathrm{BP} \\
-1, \text { for } \mathrm{LP} / \mathrm{HP} / \mathrm{AP} / \text { Notch }
\end{array}\right.
\end{gathered}
$$

where $\omega_{0}=$ cut-off frequency in radian $/ \mathrm{sec}, B W=$ bandwidth, $Q_{o}=$ quality factor and $H_{0}=$ gain. In the last three cases, having fixed the bandwidth (BW) by $R_{1}$, $\omega_{0}$ can be independently controlled by $R_{3}$ while in the first two cases $\omega_{0}$ (with $R_{2}$ and/or $R_{3}$ ) and $\mathrm{BW}$ (by $R_{1}$ ) are independently adjustable.

\section{Analysis Incorporating Nonideal Parameters}

Considering the non-ideal MO-FDCCIIs sources, two parameters, $\alpha$ and $\beta$ (where $\alpha=\left(1-\varepsilon_{i}\right)$ and $\beta=\left(1-\varepsilon_{v}\right)$, with $\varepsilon_{i}\left(\varepsilon_{i}\left\langle\langle 1)\right.\right.$ and $\varepsilon_{v}\left(\varepsilon_{v}\langle\langle 1)\right.$ denote the current and voltage tracking errors respectively) need to be considered. Incorporating these sources of error, we have the following non-ideal characterization of the MO-FDCCII:

$$
\left[\begin{array}{c}
V_{X+} \\
V_{X-} \\
I_{-Z+} \\
I_{Z-}
\end{array}\right]=\left[\begin{array}{ccccc}
0 & 0 & \beta_{11} & -\beta_{12} & \beta_{13} \\
0 & 0 & -\beta_{21} & \beta_{22} & \beta_{24} \\
-\alpha_{01} & 0 & 0 & 0 & 0 \\
0 & \alpha_{02} & 0 & 0 & 0
\end{array}\right]\left[\begin{array}{c}
I_{X+} \\
I_{X-} \\
V_{Y 1} \\
V_{Y 2} \\
V_{Y 3} \\
V_{Y 4}
\end{array}\right]
$$

Taking Equation (12) into consideration, the non-ideal expression for the output current is given by (13)

Considering above, the non-ideal expressions for $\omega_{o}$, $Q_{o}$ and $H_{0}$ are found to be:

$$
\omega_{o}=\sqrt{\frac{\alpha_{01} \alpha_{02} \beta_{13} \beta_{24}}{C_{1} C_{2} R_{2} R_{3}}} ; Q_{o}=R_{1} \sqrt{\frac{C_{2} \alpha_{01} \alpha_{02} \beta_{13} \beta_{24}}{C_{1} R_{2} R_{3}}}
$$

The non-ideal gains and realization conditions (wherever applicable) are modified as follows:

$H_{\text {OLP }}=-1$ (remains unaffected by non-ideal voltage/current gains)

$$
H_{0 \mathrm{BP}}=\alpha_{01} \alpha_{02} \beta_{24} \frac{R_{1}}{R_{2}} .
$$

$H_{\text {оНР }}=-\alpha_{02}$; where the condition of realization modifies to $\alpha_{01} \beta_{24} R_{1}=R_{2}$.

$H_{0 \text { Notch }}=-1$, if $\alpha_{02}=1$; realization condition being same as in $H P$.

$$
H_{0 \mathrm{AP}}=-1 \text {, if } \alpha_{01}=\alpha_{02}=\beta_{24}=1 \text { and } R_{2}=R_{1} \text {. }
$$

From the above, the active and passive sensitivities of the non-ideal $\omega_{0}$ and $Q_{o}$ are given by

$$
\begin{gathered}
S_{C_{1}}^{\omega_{o}}=S_{C_{2}}^{\omega_{o}}=S_{R_{2}}^{\omega_{o}}=S_{R_{3}}^{\omega_{o}}=-\frac{1}{2}, \\
S_{\alpha_{01}}^{\omega_{o}}=S_{\alpha_{02}}^{\omega_{o}}=S_{\beta_{13}}^{\omega_{o}}=S_{\beta_{24}}^{\omega_{o}}=\frac{1}{2}, S_{R_{1}}^{\omega_{o}}=0, \\
S_{C_{2}}^{Q_{o}}=S_{\alpha_{01}}^{Q_{o}}=S_{\alpha_{02}}^{Q_{o}}=S_{\beta_{13}}^{Q_{o}}=S_{\beta_{24}}^{Q_{o}}=\frac{1}{2}, \\
S_{C_{1}}^{Q_{o}}=S_{R_{2}}^{Q_{o}}=S_{R_{3}}^{Q_{o}}=-\frac{1}{2}, \quad S_{R_{1}}^{Q_{o}}=1
\end{gathered}
$$

From Equation (15) the active and passive sensitivities of $\omega_{o}$ and $Q_{o}$ are found to be in the range $-\frac{1}{2} \leq S_{x}^{F} \leq 1$, and the circuit, thus, enjoys low sensitivities.

$$
i_{0}=\frac{-\alpha_{02} i_{3}\left(s^{2}+\frac{s}{C_{2} R_{1}}\right)+\alpha_{02} \beta_{24}\left(\alpha_{01} i_{2}+i_{4}\right) \frac{s}{C_{2} R_{2}}-i_{1} \frac{\alpha_{01} \alpha_{02} \beta_{13} \beta_{24}}{C_{1} C_{2} R_{2} R_{3}}}{s^{2}+\frac{s}{C_{2} R_{1}}+\frac{\alpha_{01} \alpha_{02} \beta_{13} \beta_{24}}{C_{1} C_{2} R_{2} R_{3}}}
$$

\footnotetext{
${ }^{1}$ Although additional circuitry e.g. a multiple-output current follower will be needed at the front end of the proposed universal CM filter circuits to realize the conditions of the kind $i_{4}=i_{3}=i_{i n}$, the total amount of the hardware required, even after including such additional circuitry, will be lesser than the three-FDCCII-based universal filter structures of [1].
} 


\section{Simulation Results}

To verify the validity of the proposed configuration, current mode filters have been simulated in SPICE by making a CMOS MO-FDCCII based upon the FDCCII from [3] (Figure 3 therein) which is shown here in Figure 2.

PSPICE simulation implementation was based upon a CMOS MO-FDCCII in $0.35 \mu \mathrm{m}$ technology where the aspect ratios of the MOSFETs are shown in Table 1.

The CMOS MO-FDCCII was biased with DC power supply voltages $V_{D D}=+1.5 \mathrm{~V}, V_{S S}=-1.5 \mathrm{~V}, I_{B}=$ $35 \mu \mathrm{A}, I_{S B}=100 \mu \mathrm{A}, V_{b p}=0.2 \mathrm{~V}$, and $V_{b n}=-0.66$ $\mathrm{V}$. To achieve the filters with $f_{o}=1 \mathrm{MHz}$, the component values chosen were $R_{1}=R_{2}=0.71 \mathrm{k} \Omega, R_{3}=$ $1.39 \mathrm{k} \Omega$, and $C_{1}=C_{2}=0.16 \mathrm{nF}$. The frequency responses of LPF, BPF, HPF, Notch and APF are shown in Figure 3. Thus, a very good correspondence between theoretical values and PSPICE simulations is observed.

To test the input dynamic range of the proposed filters, the simulation of the band-pass filter as an example has been done for a sinusoidal input signal of $f_{o}=1 \mathrm{MHz}$. Figure 4 shows that the input dynamic range of the filter extends up to amplitude of $300 \mu \mathrm{A}$ without significant distortion. The dependence of the output harmonic distortion on the input signal amplitude is illustrated in Figure 5.

Although FDCCII-based filters have been proposed by many authors as [1,3-6], with the exception of [1] (Figure 11 therein), [6] (Figure 2 therein), all others deal with voltage-mode filters.

In view of this, a comparison with MISO-type CM universal biquads using FDCCIIs presented recently in [1] (Figure 11 there in) and [6] (Figure 2 therein) is now in order. When compared with the circuit of [1], the circuit of Figure 2 has the advantage of using only one active building block (one FDCCII) as against three FDCCII's in biquads proposed in [1] and use of all grounded passive elements (AGPE) which is an attractive feature for IC implementation. On the other hand, when compared with the circuit of [6] (Figure 2 there in) our circuit has

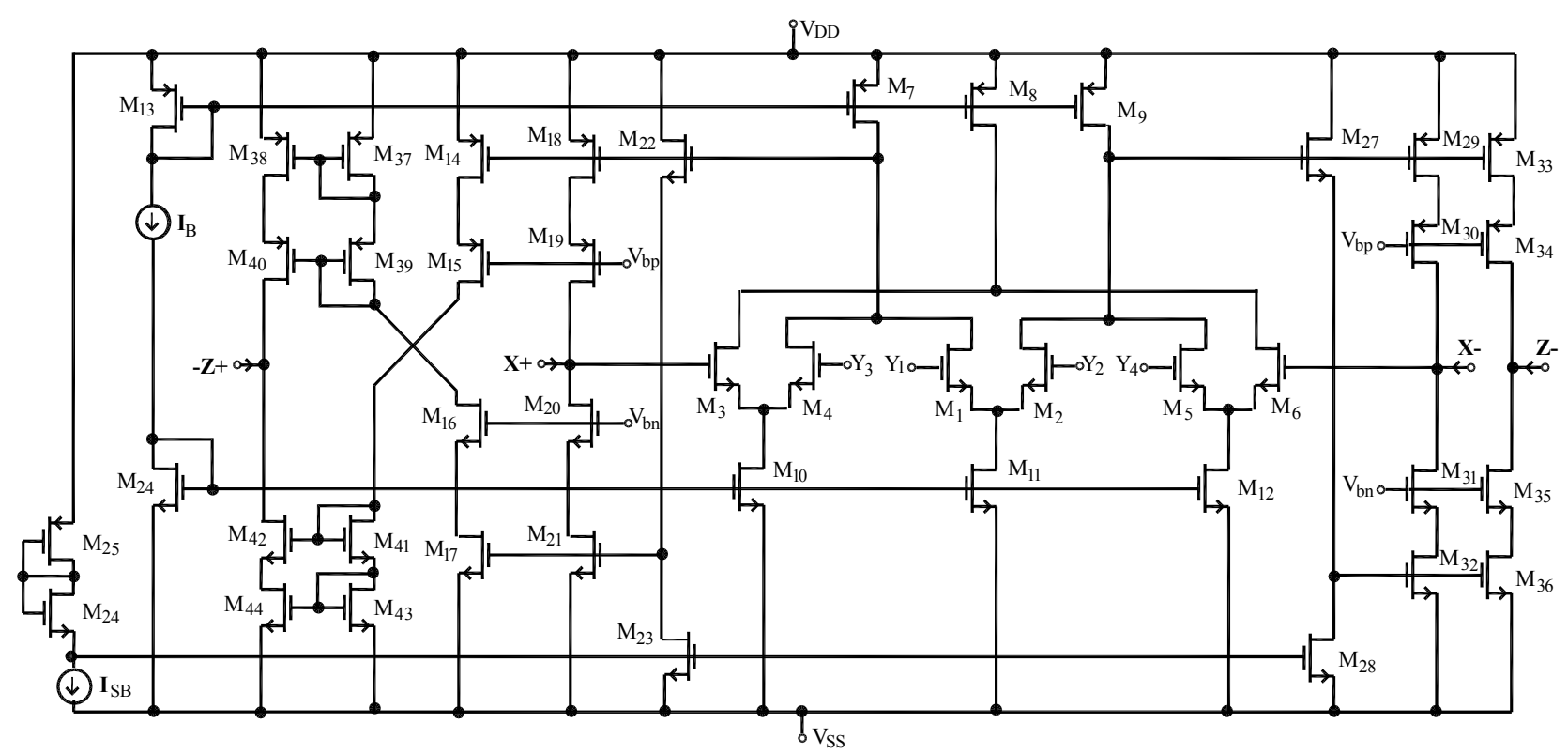

Figure 2. CMOS realization of the FDCCII.

Table 1. Aspect ratios of MOSFETs.

\begin{tabular}{lc}
\hline MOS transistors & W/L \\
\hline $\mathrm{M}_{1}-\mathrm{M}_{6}$ & $0.7 / 0.35$ \\
$\mathrm{M}_{7}, \mathrm{M}_{8}, \mathrm{M}_{9}, \mathrm{M}_{13}$ & $15 / 1.2$ \\
$\mathrm{M}_{10}, \mathrm{M}_{11}, \mathrm{M}_{12}, \mathrm{M}_{24}$ & $0.7 / 0.35$ \\
$\mathrm{M}_{14}, \mathrm{M}_{15}, \mathrm{M}_{18}, \mathrm{M}_{19}, \mathrm{M}_{25}, \mathrm{M}_{29}, \mathrm{M}_{30}, \mathrm{M}_{33}, \mathrm{M}_{34}, \mathrm{M}_{37}, \mathrm{M}_{38}, \mathrm{M}_{39}, \mathrm{M}_{40}$ & $20 / 0.35$ \\
$\mathrm{M}_{16}, \mathrm{M}_{17}, \mathrm{M}_{20}, \mathrm{M}_{21}, \mathrm{M}_{26}, \mathrm{M}_{31}, \mathrm{M}_{32}, \mathrm{M}_{35}, \mathrm{M}_{36}, \mathrm{M}_{41}, \mathrm{M}_{42}, \mathrm{M}_{43}, \mathrm{M}_{44}$ & $25 / 0.35$ \\
$\mathrm{M}_{22}, \mathrm{M}_{23}, \mathrm{M}_{27}, \mathrm{M}_{28}$ & $0.35 / 0.35$ \\
\hline
\end{tabular}




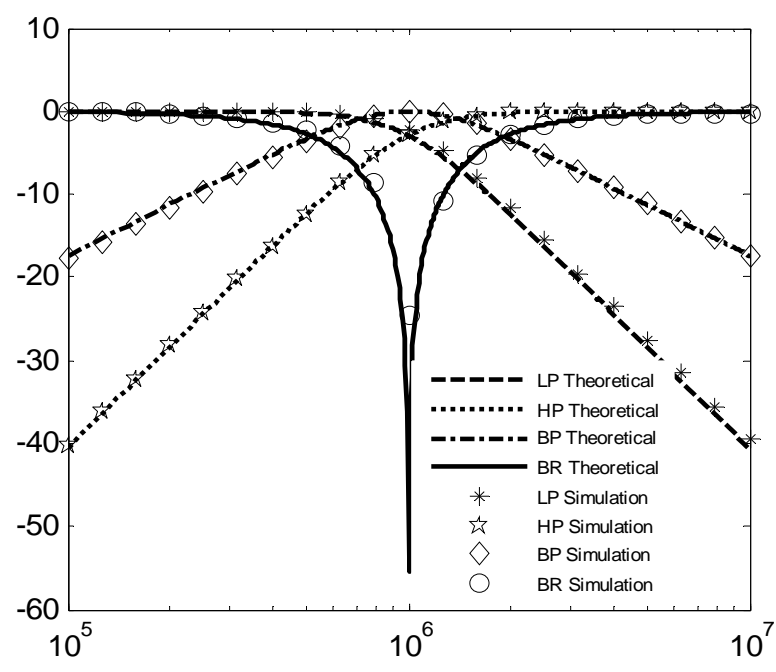

(a)

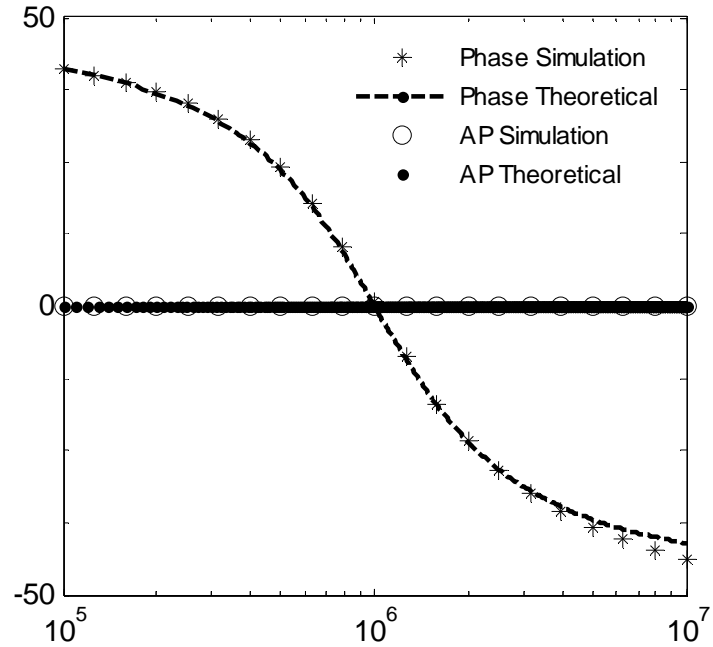

(b)

Figure 3. PSPICE simulation results. (a) Gain response of LPF, BPF, HPF and Notch. (b) Gain and phase response of APF.

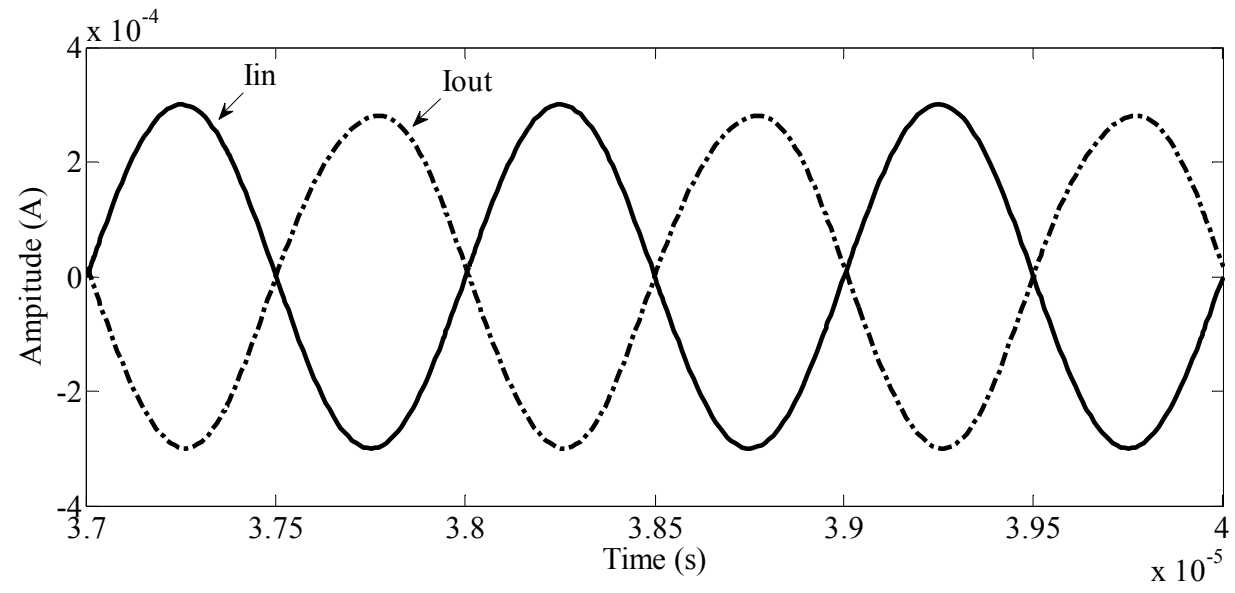

Figure 4. Input and output waveforms of the band-pass filter of the proposed circuit for $1 \mathrm{MHz}$ sinusoidal input current of $300 \mu \mathrm{A}$.

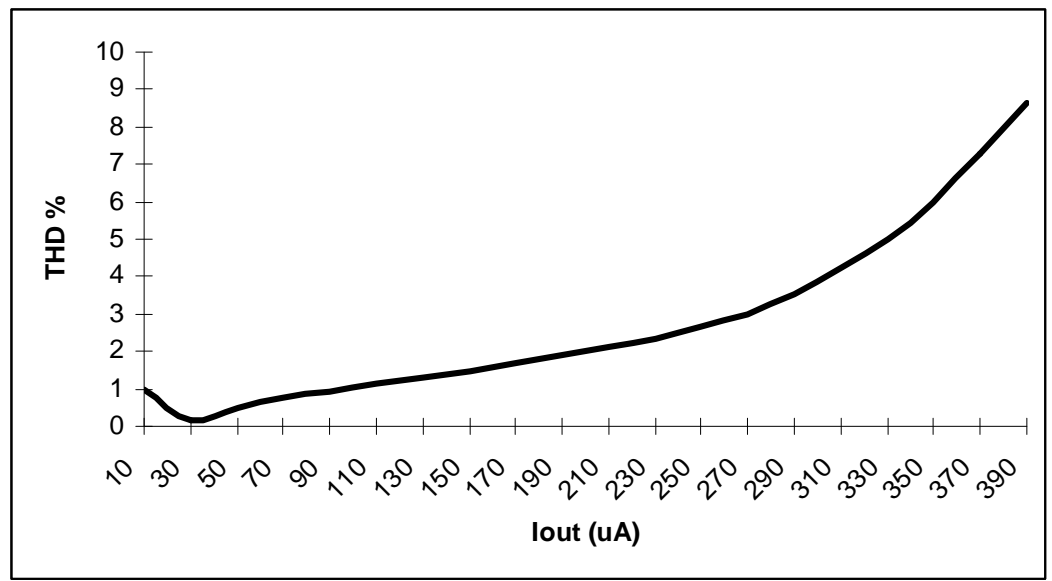

Figure 5. Dependence of output current total harmonic distortion on input current amplitude for the band-pass filter realized from the proposed configuration. 
the advantages of independent tunability of BW or $Q_{o}$ which is not feasible in the quoted circuit of [6] which also needs two outputs to implement APF. Our FDCCII has nine terminals in contrast to the FDCCII in [6] which has eleven terminals to implement the biquad filter.

The comparison with [9] and [10] is now in order, The circuit of [9] (Figure 8 there in) is also current-mode MISO type and uses five grounded passive elements but used two FDCCIIs (the first has ten terminals and the other has nine terminals to implement the biquad filter) and not independent tunability of BW or $Q_{o}$.

The circuit of [10] although uses one FDCCII (eleven terminals to implement the biquad filter in current -mode and voltage mode) but has one floating resistance and needs two outputs to implement LPF and APF.

\section{Concluding Remarks}

A method has been presented by which the FDCCIIbased CM SRCOs of [2] can be reconfigured as MISO-type universal biquads offering realizations of all the five standard filter functions also, thereby enhancing their capabilities. One exemplary biquad resulting from the application of the proposed method was presented and its workability was demonstrated by SPICE simulation using an FDCCII implementation in $0.35 \mu \mathrm{m}$ CMOS technology.

The methodology presented here could also be applied to all other SRCOs published earlier using other kinds of active building blocks thereby giving rise to a large number of new MISO-type CM universal biquads, some of which may possess some interesting features. This, however, is left for further investigations.

\section{Acknowledgements}

The authors wish to thank an anonymous reviewer for his constructive feedback, which has been helpful in improving the presentation. The material presented here has its origin in an earlier unpublished report ${ }^{2}$ of Analog Signal Processing Research Lab of NSIT, where part of this work was performed.

\section{References}

[1] A. A. El-Adawy, A. M. Soliman and H. O. Elwan, "A Novel Fully Differential Current Conveyor and Its Applications for Analog VLSI," IEEE Transactions on Circuits and Systems II: Analog and Digital Signal Processing, Vol. 47, No. 4, April 2000, pp. 306-313. doi: $10.1109 / 82.839666$

${ }^{2}$ R. Senani, "Re-Configuring FDCCII-Based SRCOs into Universal Current mode Biquads", TCASII ID-2267, November 14, 2003 (Unpublished).
[2] C. M. Chang, B. M. Al-Hashimi, H. P. Chen, S. H. Tu and J. A. Wan, "Current Mode Single Resistance Controlled Oscillators Using Only Grounded Passive Elements," Electronics Letters, Vol. 38, No. 39, 2002, pp. 1071-1072. doi:10.1049/el:20020714

[3] H. P. Chen, "Single FDCCII-Based Universal VoltageMode Filter," International Journal of Electronics and Commun (AEU), Vol. 63, No. 9, 2009, pp. 713-719. doi:10.1016/j.aeue.2008.05.012

[4] F. Gür and F. Anday, "First-Order Allpass SectionsBased High-Input Low-Output Impedance Voltage-Mode Universal Filter Using FDCCIIs," Proceeding of 18th European Conference on Circuit Theory and Design, Seville, 27-30 August 2007, pp. 428-431.

[5] C. M. Chang and H. P. Chen, "Single FDCCII-Based Tunable Universal Voltage-Mode Filter," Circuits Systems Signal Processing, Vol. 24, No. 2, 2005, pp. 221227. doi:10.1007/s00034-004-0422-7

[6] C. M. Chang, B. M. Al-Hashimi, C. L. Wang and C. W. Hung, "Single Fully Differential Current Conveyor Biquad Filters," IEE Proceeding of Circuits Devices System, Vol. 150, No. 5, 2003, pp. 394-398. doi:10.1049/ip-cds:20030468

[7] S. A. Mahmoud, M. A. Hashiesh and A. M. Soliman, "Low-Voltage Digitally Controlled Fully Differential Current Conveyor," IEEE Transactions on Circuits and Systems I, Vol. 52, No. 10, 2005, pp. 2055-2064. doi:10.1109/TCSI.2005.852922

[8] H. A. Alzaher, "CMOS Highly Linear Fully Differential Current Conveyor," Electronics Letters, Vol. 40, No. 4, 2004, pp. 214-216. doi:10.1049/el:20040183

[9] F. Gür and F. Anday, "Simulation a Novel Current-Mode Universal Filter Using FDCCIIs," Analog Integrated Circuits and Signal Processing, Vol. 60, 2009, pp. 231236. doi:10.1007/s10470-009-9293-y

[10] C. N. Lee and C. M. Chang, "Single FDCCII-Based Mixed-Mode Biquad Filter with Eight Outputs," International Journal of Electronics and Communication (AEU), Vol. 63, No. 9, 2009, pp. 736-742. doi:10.1016/j.aeue.2008.06.015

[11] R. Senani and A. K. Singh, "A New Universal CurrentMode Biquad Filter," Frequenz, Vol. 56, 2002, pp. 55-59.

[12] R. Senani, A. K. Singh and V. K. Singh, "New Tunable SIMO-Type Current-Mode Universal Biquad Using Only Three MOCCs and All Grounded Passive Elements," Frequenz, Vol. 57, 2003, pp. 160-161.

[13] J. W. Horng, "Current Conveyor Based Current-Mode Universal Biquadratic Filter," Journal of the Chinese Institute of Electrical Engineering, Vol. 9, 2002, pp. 147150.

[14] H. Y. Wang and C. T. Lee, "Versatile Insensitive Current Mode Universal Biquad Implementation Using Current Conveyors," IEEE Transactions CAS-II. Analog and Digital Signal Processing, Vol. 48, 2001, pp. 409-413.

[15] M. Siripruchyanun and W. Jaikla, "Cascadable Current-Mode Biquad Filter and Quadrature Oscillator Using 
DO-CCCIIs and OTA," Circuits Systems and Signal Processing, Vol. 28, No. 1, 2009, pp. 99-110. doi:10.1007/s00034-008-9072-5

[16] E. Yuce and S. Minaei, "Universal Current-Mode Filters and Parasitic Impedance Effects on the Filter Performances," International Journal of Circuit Theory and Applications, Vol. 36, No. 2, 2008, pp. 161-171. doi:10.1002/cta.418

[17] S. Minaei, "Electronically Tunable Current-Mode Universal Biquad Filter Using Dual-X Current Conveyors," Journal of Circuits, Systems, and Computers, Vol. 18, No. 4, 2009, pp. 665-680. doi:10.1142/S0218126609005186
[18] C.-M. Chang, B. M. Al-Hashimi and J. N. Ross, "Unified Active Filter. Biquad Structures," IEE Proceeding of Circuits Devices System, Vol. 151, No. 4, 2004, pp. 273277. doi:10.1049/ip-cds:20040132

[19] R. Senani, "New Universal Current Mode Biquad Employing All Grounded Passive Components But Only Two DOCCs," Journal of Active and Passive Electronic Devices, Vol. 1, 2006, pp. 281-288.

[20] R. Senani, "A Simple Approach of Deriving Single-Input-Multiple-Output Current Mode Biquad Filters," Frequenz, Vol. 50, No. 5-6, 1996, pp. 124-127. 